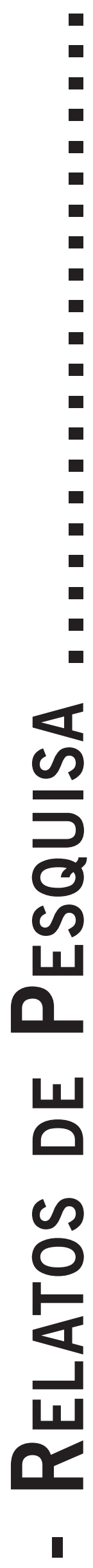




\title{
A EXPERIÊNCIA DA PRIMEIRA SESSÃO DE HEMODIÁLISE: UMA INVESTIGAÇÃO FENOMENOLÓGICA
}

\author{
La Experiéncia de la Primera Sesión de Hemodiálisis: una Investigación Fenomenológica
}

The Experience of the First Session of Hemodialysis: a Phenomenological Investigation

\author{
RHAYSSA FERREIRA BRITO \\ TElma Costa de Avelar \\ Marcus Tulio Caldas \\ Luciana Fernandes Santos \\ Fernanda Paula dos Santos Castro \\ Brena da CRUz Prado
}

\begin{abstract}
Resumo: O presente estudo faz parte de uma pesquisa que procurou investigar a experiência da primeira sessão de hemodiálise para o paciente renal crônico a luz da fenomenologia. O objetivo deste estudo é compreender o significado de se submeter à Hemodiálise de urgência a partir da experiência do Doente Renal Crônico. Atrelado a este, intenciona-se descrever o significado de submeter-se a hemodiálise, investigar a compreensão do Doente Renal Crônico e pesquisar sua expectativa quanto aos cuidados relacionados à saúde e seus hábitos de vida. Este estudo baseia-se na proposta de Estudo de Caso que permite uma visão em maior profundidade acerca dos fenômenos humanos. Para análise do material, foi utilizado o Método Fenomenológico de Investigação em Psicologia de Amedeo Giorgi de metodologia qualitativa, que estuda o sentido da experiência humana nas suas mais variadas relações com o mundo. Foi escolhido para colaborar com o estudo um participante em sua primeira sessão de hemodiálise acompanhado no Hospital das Clínicas de Pernambuco. Este estudo aponta que a experiência da primeira sessão de hemodiálise é algo singular para os sujeitos e que apesar do avanço tecnológico e as abordagens médicas, aceitar tal condição depende do paciente e a sua forma de relacionar-se com o adoecimento.
\end{abstract}

Palavras-chave: Diálise renal; Psicologia em saúde; Doença renal crônica.

Abstract: This study is part of a search that sought to investigate the experience of the first hemodialysis session for the chronic renal patient in the light of phenomenology. The present study aims to understand the meaning of submitting to the Hemodialysis urgency from the chronic renal patient experience. In addition to this, it intends to describe the meaning of undergoing hemodialysis, investigate the Chronic Renal patient understanding and search your expectations for the care related to his or her health and lifestyle habits. This study is based on a case study proposal that allows a vision of greater depth about human phenomena. For material analysis it was used the phenomenological Research's Method in Psychology of Amedeo Giorgi in qualitative methodology, which studies the sense of human experience in its various relations with the world. It was chosen to collaborate with this study a participant in its first hemodialysis session that was accompanied at Hospital das Clínicas de Pernambuco. This study points to a singular experience for the subjects in the first session of hemodialysis despite the technological advancement and the medical approaches, accept this condition depends on the patient and its way of relating with the illness.

Keywords: Renal dialysis; Behavorial medicine; Renal insufficiency.

Resumen: Este estudio es parte de una investigación científica que intentó investigar la experiencia de la primera sesión de hemodiálisis para pacientes renales crónicos la luz de la fenomenología. El objetivo de este estudio es comprender el significado que se someten a hemodiálisis de emergencia de la experiencia del enfermo renal crónica. Junto a esto, se tiene la intención de describir el significado de hemodiálisis, investigar la comprensión del enfermo renal crónica y buscar sus expectativas para la atención relacionada con los hábitos de salud y estilo de vida. Este estudio se basa en la propuesta de estudio de caso que permite una visión más a fondo acerca de los fenómenos humanos. Para el análisis del material, se utilizó el método de investigación fenomenológica en Psicologia de Amedeo Giorgi de la metodología cualitativa, que estudia el significado de la experiencia humana en sus múltiples relaciones con el mundo. Fue elegido para participar en el estudio de un participante en su primera sesión de hemodiálisis en el Hospital de Clínicas de Pernambuco. Este estudio muestra que la experiencia de la primera sesión de hemodiálisis es algo único para las personas e el tema ya pesar de los avances tecnológicos y los enfoques médicos, aceptar estas condiciones depende del paciente y la forma en que se relaciona con la enfermedad.

Palabras clave: Diálisis renal; Medicina de la conducta; Insuficiencia renal crónica. 


\section{Introdução}

\section{Doença Renal Crônica}

As Doenças Crônicas não Transmissíveis (DCNT) configuram-se como um grave problema de saúde pública em nível mundial, colocando em risco a saúde e o desenvolvimento de toda a população. Os países subdesenvolvidos e em desenvolvimento são os mais afetados (Schimdt, 2011). A porcentagem de óbitos atribuídos às doenças crônicas no Brasil é alarmante, em 2007 aproximadamente $72 \%$ das mortes em todo o país foram relacionadas às DCNT, tais como doenças cardiovasculares, respiratórias, metabólicas e renais. Com o avanço da tecnologia da saúde, o desenvolvimento econômico e social, observa-se que causas de mortalidade se distinguem totalmente em relação a 1930 quando maior parte dos óbitos ocorriam por doenças infectocontagiosas (Silva-Junior, 2009).

Atribuir a uma doença o status de cronicidade carece que esta traga consigo uma série de impactos psicossociais ao indivíduo, família e ao meio em que vive. Por não existir tratamento que vise à cura, dependendo da sua característica e malignidade, pode acarretar incapacidade total ou parcial do indivíduo, propiciando que o mesmo venha a sofrer mais internamentos hospitalares, careça de cuidados médicos constantes e de tecnologias e/ou medicamentos de alto custo (Rolland, 1998).

Dentre as principais doenças crônicas, destaca-se a Doença Renal Crônica (DRC) por sua elevada taxa de mortalidade e morbidade. Doenças renais e urológicas levam a óbito cerca de 850 mil pessoas anualmente sendo considerada como a $12^{\mathrm{a}}$ causa de morte no mundo (Who, 2014). A cada ano tem se observado um aumento significativo no diagnóstico da DRC no Brasil (Grassmann, Gioberge, Moeller \& Brown, 2005), que em seus estágios mais avançados impossibilita que o rim funcione de maneira adequada, causando a Insuficiência Renal Crônica (IRC) e necessitando de métodos eficazes para substituição da função renal.

No Brasil, a Hipertensão Arterial Sistêmica (HAS), seguida das Glomerulonefrites e Diabetes Melito (DM), são as principais causas para o aparecimento da Doença Renal Crônica (Barros, 2009). Independentemente da causa do aparecimento da Doença Renal Crônica, suas complicações (acidose metabólica, anemia, desnutrição, etc.), a falência da função renal (FFR) e óbito, são conseqüências que poderiam ser evitadas caso a doença tivesse um diagnóstico rápido e tratamento adequado (Bastos, 2010).

A DRC divide-se em três grupos: doenças primárias, sistêmicas e que afetam o trato urinário ou urológico. Apesar de ser um órgão complexo, o rim apresenta capacidade de adaptar-se, mesmo quando o órgão apresenta alguma disfunção. Por esta capacidade, os sintomas podem levar anos para serem notados, levando progressivamente o portador da DRC a diminuir a função renal, até que chegue à condição de insuficiência, ou seja, menos que 10\% da função renal total (Marques, Pereira \& Ribeiro, 2005).

\section{Terapia de Substituição Renal}

Quando o paciente é diagnosticado com DRC em condições de insuficiência renal é indicado iniciar o tratamento dialítico, pois sem o funcionamento correto do rim os sistemas e os órgãos podem sofrer danos irreversíveis (Barreto et al, 2014). Ao médico nefrologista compete unir os achados clínico-laboratoriais, sintomas urêmicos, indicadores nutricionais, para fomentar a decisão pela Diálise ou Transplante Renal. Em linhas gerais dialisar significa transportar água e solutos através de uma membrana artificial (Hemodiálise) ou biológica (Diálise Peritoneal) (Barros, 2009).

Alguns estudos apontam que o acompanhamento prévio com um nefrologista tem boa influência no decorrer do tratamento. Os pacientes sentem-se mais seguros, recebem o suporte médico adequado, são preparados para o momento certo para o início da diálise, podem escolher o tipo de terapêutica mais recomendada para seu caso e tem um bom prognóstico no decorrer do primeiro ano de diálise. (Jones, Roderick, Harri \& Rogerson, 2006).

Diante da organização atual do sistema de saúde público brasileiro, o acesso deficitário aos serviços especializados, a progressão silenciosa da doença renal, podem contribuir para um prognóstico negativo da patologia. Muitas vezes nas primeiras consultas médicas, o início da TRS (Terapia Renal Substitutiva) já é previsto devido à rápida progressão da doença (Pandovani, Schor \& Laranja, 2012).

As terapias de substituição renal são procedimentos de alta complexidade, que exigem o uso de tecnologias de ponta, um corpo de profissionais treinados e uma equipe multidisciplinar para que possam abranger todos os aspectos da DRC (Seco \& Castilho, 2007). Por a DRC ser considerada um problema de saúde pública, devido às altas taxas de morbidade e mortalidade, exerce também um impacto significativo sobre a qualidade de vida (Martins \& Cesarino, 2005). Normalmente as sessões de hemodiálise duram em média quatro horas e são realizadas três vezes por semana. Por ser caracterizada como um tratamento de alta complexidade devido à necessidade de o paciente ser constantemente monitorado durante as sessões, a fim de evitar complicações graves ou emergências médicas (Valle, Souza \& Ribeiro, 2013).

\section{Repercussão do Diagnóstico da Doença Renal Crônica}

O diagnóstico da DRC pode trazer uma série de impactos na vida de seu portador. É um tratamento rigoroso que pode apresentar mudanças na esfera familiar, social, sexual e profissional, concomitantemente prejudicando sua qualidade de vida. Ao submeter-se a procedimentos que por muitas vezes são extremamente invasivos, restrições hídricas, alimentares, e ao próprio processo de diálise, ocasiona grande dependência de familiares ou acompanhantes, modificando totalmente a rotina do paciente (Chan, Brooks, Erlich \& Suranyi, 2009). 
Os pacientes submetidos à Hemodiálise são acometidos por diversas limitações biopsicossociais que interferem diretamente no enfrentamento da doença e na qualidade de vida. Aceitar-se enquanto Insuficiente Renal Crônico significa adaptar-se à rotina do tratamento hemodialítico ocasionando repercussões significativas no contexto social, familiar, físico e emocional do indivíduo (Ferreira \& Filho, 2011). A experiência de ser Insuficiente Renal Crônico que realiza hemodiálise é singular e significativa para cada sujeito, os modos de vivências e enfrentamento utilizados influenciam diretamente na qualidade de vida e adesão do tratamento destes pacientes.

Por tal condição que a doença renal impõe quando se precisa utilizar a hemodiálise, são fatores que aumentam o estresse e também podem acometer em problemas para tal portador como isolamento social, perda da ocupação laboral, dependência dos benefícios sociais, dificuldade de locomoção, adaptação pela perda da autonomia, alteração da imagem corporal e o medo de morrer constante. O apoio psicoterápico, familiar e social, podem ser úteis para ressignificação (Machado \& Car, 2003).

\section{Objetivos}

O objetivo deste estudo de caso é compreender experiência de se submeter à primeira sessão de hemodiálise a partir da experiência do Doente Renal Crônico. Atrelado a este, intenciona-se descrever o significado de submeter-se a hemodiálise, investigar a compreensão do Doente Renal Crônico e pesquisar sua expectativa quanto aos cuidados relacionados à saúde e seus hábitos de vida.

\section{Metodologia}

O estudo de caso dá a possibilidade de se estudar com maior profundidade um fenômeno, grupo ou instituição, pois considera suas diversas dimensões. Um de seus pressupostos é considerar o caso numa totalidade e o relacionamento entre as partes. Segundo Gil (2009), os estudos de caso, embora estudando eventos contemporâneos, favoreceriam a apreensão das mudanças qualitativas, pois o caso em estudo pode ser entendido também como processo. Nesta pesquisa, foi utilizada a perspectiva do estudo de caso descritivo, que tem a intenção de descrever um fenômeno, reconhecer as suas diversas manifestações e descrevê-las. O estudo de caso descritivo único tem a intenção de lançar um maior aprofundamento acerca de situações específicas que merecem ser analisadas com maior detalhamento.

Como o objetivo do estudo é o de investigar a experiência da primeira sessão de hemodiálise foi escolhido um participante em sua primeira sessão de hemodiálise acompanhado no Hospital das Clínicas de Pernambuco. A entrevista foi realizada em uma sala reservada, proporcionando privacidade ao colaborador. Inicialmente foi apresentada a proposta do estudo a após o seu consentimento através do Termo de Consentimento Livre e Esclarecido (TCLE) foi iniciada a coleta dos dados.

A coleta dos dados foi realizada através de uma entrevista semidirigida com as algumas questões disparadoras: 1) O que você entende por hemodiálise?; 2) Você sabia que em algum momento iria realizar hemodiálise?; 3) O que significou para você se submeter a hemodiálise de urgência; 4) Como você se sente em realizar hemodiálise?. Os dados foram gravados e transcritos com o consentimento do colaborador para posterior análise, respeitando os critérios da pesquisa fenomenológica em disponibilizar um diálogo que proporcione a expressão das experiências do sujeito.

A Psicologia Fenomenológica tem como objeto de estudo a vivência intencional, que é o sentido da experiência humana. O objetivo de utilizar o método fenomenológico de investigação em de Psicologia consiste em compreender como o sujeito descreve a sua experiência. Para alcançar tal objetivo é utilizada a entrevista fenomenológica, que consiste em um instrumento no qual traduz uma forma diferente para se construir o significado sobre as atitudes humanas.

O Método Fenomenológico de Investigação em Psicologia foi utilizado neste estudo para realizar a análise dos dados obtidos. Foi criado por Amedeo Giorgi e Daniel Souza e divide-se em quatro partes. A primeira se refere a Estabelecer o Sentido Geral, que consiste em realizar uma leitura da entrevista sem formular hipóteses nem focar em partes especificas, tendo assim uma compreensão geral do conteúdo da entrevista do sujeito. A segunda parte se consiste em reler a entrevista com o objetivo de dividi-la em partes menores, sempre que houver uma mudança de sentido na fala do sujeito, estas divisões são chamadas de unidades de significado. Na terceira parte o pesquisador irá descrever os significados psicológicos de acordo com a descrição do sujeito na entrevista. E por fim, a última parte do método o pesquisador irá usar as unidades de significado para explicar a estrutura psicológica da experiência relatada pelo sujeito (Giorgi \& Souza, 2010).

\section{Resultados e Discussão}

\section{Experiência Psicológica da hemodiálise}

1. O conhecimento científico não supera os afetos. É um procedimento para a regularização das taxas... Fica a enfermidade no corpo e pode causar diversos problemas (...). Sempre tive um medo por conta de coisas que aconteceram na minha família, que me levaram a fazer exames, hoje é surpresa para mim.

O participante contextualiza a hemodiálise através do discurso científico, mas sua experiência é compreendida de forma pessoal. Apesar de entender para que serve o procedimento de hemodiálise, se surpreende ao ser 
diagnosticado com a Doença Renal e precisar da diálise. Diante disto pode-se observar que apesar do conhecimento científico ter sua importância na experiência do processo diagnóstico, a dimensão humana, das experiências e dos afetos não deve ter menor valia que a do conhecimento técnico-científico. "Para compreender o homem e sua subjetividade, o cuidado com a saúde não envolve apenas o caráter técnico-científico, necessita de um modo de cuidado que acolha também as nuances existenciais e afetivas do ser humano" (Olivieri, 1985).

\section{Experiência caótica no processo de diagnóstico}

Deu falta de ar, passei mal (...). No outro dia procurei a "verdade" daquilo na minha cidade (...) quase que eu morria de tanto remédio que eles me deram... Depois vim ao HC porque não gosto de fazer nada na minha cidade"

O participante passa por uma experiência caótica no processo de descobrimento da doença, trás desconfiança e ambivalência com os serviços de saúde que o assistem. A experiência do surgimento da doença se dá de forma desorganizada. A partir do momento em que se há o vestígio da doença no homem a experiência de ser doente é compreendida tanto como a luta do organismo versus um sintoma que surge como também é compreendida como o duelo interno do corpo com a injúria que se instalou, então a partir destes sintomas o participante sente-se doente. "A doença difere da saúde, o patológico do normal, como uma qualidade difere da outra, quer pela ausência de um princípio definido, quer pela reestruturação da totalidade orgânica” (Canguilhem, 2000, p. 21).

\section{Experiência do mal estar}

Vinha bem, até este sábado que eu me senti mal depois de ter comido charque. Eu senti uma falta de ar, uma vertigem... não igual a passada... eu pensava que ia me desligar, assim, morrer.

Para o participante, a experiência que passa ao sentir o mal estar é algo dramático. Quando este sente a doença no corpo os sintomas da doença se apresentam e mesmo passa a ter uma experiência caótica. "A doença, esse fator de perturbação de alguma coisa que quase não percebemos quando de sua impermutabilidade, nos torna presente ao extremo nossa corporeidade” (Gadamer, 2006, p. 80).

\section{A experiência corporal não o faz sentir-se portador da DRC}

O médico disse que eu tinha que ficar internado, eu entrei na medicação logo. Disse que eu era um hipertenso crônico e tinha 99\% de chances de fazer a diálise. Não aceitar a situação, eu era normal, tava normal em casa, depois dessa vertigem eu fui a tantos lugares, aí comi tudinho, não bebi (bebida alcoólica), mas tomei muito sorvete e não tive nada.
Apesar de descrever a situação de forma técnica, o procedimento médico de informar-lhe as porcentagens de chance que tinha para entrar em diálise, a relação do paciente com a corporeidade ainda está muito ligada. Não acredita estar doente, após sentir-se mal conseguiu conduzir suas atividades normalmente, não se considerando doente. Alegando desta forma não aceitar a condição que poderia entrar no processo de diálise, pois, estava sentindo-se bem, seu corpo não sofria nenhum sintoma da doença.

\section{Desconfiança no conhecimento da equipe médica}

Era um negócio que teria que ser decidido passo a passo, de repente a pessoa vê uma necessidade tão tamanha e a gente fica assim... sem entender, porque se eu tinha um tempozinho até... Primeiro eu tinha que resolver outras coisas logo, pra depois...

O participante demonstra uma desconfiança no conhecimento técnico-científico, vê como uma decisão que deveria ser tomada junto a ele, de acordo com o que estava sentindo. Confia no que sente o que não justifica ser a doença renal, sente-se violado por não compreenderem que sua experiência de adoecimento perpassa pela esfera corporal. Sentir-se doente significa ser aquele sujeito para o qual falta alguma coisa (Gadamer, 2006).

\section{Traz a experiência emocional como segundo plano} Como eu sei que deve estar envolvida a parte nervosa eu acho que pode ser, eu fico na minha, calado. Eu acho pior agora né... com a esperança de ficar bom. Eu fiquei nervoso pelo fato de ter assim aquele medo diante de ter o pescoço, mas, com a consciência tinha que ser resolvido meu problema da pressão, que eu não ficaria o tempo todo com pressão alta... Acontece, né? Horrível como uma coisa ruim, mas com o pensamento que poderia ser para o bem, aí encarar a realidade como ela deve ser encarada...

O participante relata sua experiência de iniciar a hemodiálise como algo passivo de lidar. Trás um sentimento de dúvida na sua confiança no procedimento técnico, algo que pode melhorar seu estado de saúde, mas que prefere não se envolver emocionalmente deixa os afetos de lado para lidar com a experiência da inserção do cateter de hemodiálise, experiência bastante impactante, mas trazendo de modo objetivo a compreensão que o procedimento melhoraria sua hipertensão arterial. A relação de causa e efeito é bastante presente nessa experiência do participante: para regularizar suas taxas bioquímicas é necessário deixar a experiência emocional distante.

\section{Sentimento de ambivalência}

Eu tenho um pouquinho de conhecimento, sei por que acontecem as coisas. Significou uma saída do problema, da cura da pressão alta e da regularização das ta- 
xas... significou isso, né? Agora acredito na mudança do corpo em si só, a intervenção às vezes é tudo, às vezes eu acho que tem que se tentar outros recursos... pelo menos no meu caso eu estava fazendo tudo direito, me locomovendo para todo canto, estudando, fazendo tudo, de repente a surpresa de estar envolvido na diálise.

Novamente o participante trás em seu discurso a questão do sentimento de ambivalência. Apesar de compreender de forma científica para que serve e como funciona a hemodiálise, acredita que a decisão tomada pela equipe médica solucionou a saída do problema, mas algo tratado na forma objetiva: regularização das taxas e diminuição da hipertensão arterial. Enxerga que em seu caso, não necessariamente é necessária à intervenção técnica, pois como estaria seguindo a risca as recomendações médicas em relação a seus hábitos de vida, sentia-se ativo, não se sentia doente, portador da doença renal crônica.

A fenomenologia destitui a realidade fatídica da natureza, dos homens, dos animais, do eu, mas, compreende que a alma, o sentido de tudo em que se está em contato, de uma forma que as coisas não estão somente presentes diante a mim, mas germinam de mim (Husserl, 2006).

"A medicina moderna se viu, então logicamente, confrontada, sobretudo com doenças crônicas, para as quais se colocam outras tarefas. Nelas depende o cuidado dedicado ao doente, no que também se exige o cuidado espiritual. $\mathrm{O}$ doente tem de aprender a aceitar a doença e a viver com ela, à medida que a doença permita. Deve-se aprender a aceitar viver com a doença, a aceitar uma doença crônica - sim, até mesmo uma doença crônica - sempre que se trata de vida ou morte" (Gadamer, 2006, p. 84).

\section{Espiritualidade como superação}

A mudança está sendo estranha, horrível, fico tonto, não sei se isso depois passa, não sei se é por causa do ferimento no pescoço (cateter) puxando... não sei se é isso. Mas, eu vou vencer se Deus quiser. Eu acho... ela vai (a hemodiálise), ela vai, resolver meu problema de pressão, se Deus quiser eu vou me livrar dele e regularizar as minhas taxas.

Durante toda a entrevista é o primeiro momento que o participante insere a esfera espiritual como sentido de falta de esperança em sua condição após o diagnóstico de ser portador da doença renal, Deus entra em seu discurso. Dependendo da ordem divina, ele poderá superar a angústia que sentida e as experiências emocionais negativas advindas com o processo de diálise.

"A angústia está em extrema relação com o aperto, com a repentina exposição à amplitude e ao estranho. Todos nós temos algo da nossa experiência primordial em muitas palavras da nossa língua e podemos escutar a partir daquelas palavras. A angústia vem desta forma como uma constituição básica da vida, a de se arremessar do estreito ao vasto" (Gadamer, 2006, p. 156).

\section{Ocupação como definição de ser si mesmo}

Tão falando que eu não vou poder trabalhar mais, vou ter de me aposentar... Eu acho muito ruim porque eu sei lá, tenho sonhos feito todo mundo tem, estudar, fazer cursos e trabalhar, agora eu não vou ter mais a oportunidade... Não vou tirar a oportunidade de outra pessoa, né? Porque pessoas em hemodiálise não tem muita chance de entrar no mercado de trabalho não, já basta a idade e com algum problema...

Nesta parte o participante trás a esfera psicossocial a sua experiência, nesta fala se considera doente, portador da DRC e compreende que por conta da sua condição atual será difícil voltar a sua ocupação laboral, algo que revela o seu ser.

"No cotidiano nós nos definimos a partir daquilo de que nos ocupamos. Cada um tem o seu negócio, o seu ofício, a sua profissão. E passa a compreender o seu ser-no-mundo a partir das perspectivas abertas pelas suas ocupações. Elas podem ser, sempre de novo, uma chance para ele vir a ser si mesmo" (Fernandes, 2011, p. 24).

\section{A isenção da responsabilidade}

As forças estranhas estão ocultando para isso... O fato de às vezes a pessoa ter um tipo de pessoa que mora perto da sua casa, as vezes ela age de um jeito e depois de outro, a gente sempre fica na expectativa de saber quem é a pessoa e de repente a pessoa não presta é um mal caráter. Depois ela age da maneira mais baixa possível... esses negócios de bruxaria, de coisas assim... coisas ocultas. Antes eu tinha uma vida normal, não sou uma pessoa exagerada em nada, tudo regularizado e me pega assim esse problema. Porque uma pessoa de um dia para a noite não tem um diagnóstico mudado tão radicalmente assim. Sou uma pessoa que vivi na igreja que vivo um pouco afastado agora, mas eu tenho meus relacionamentos com o pessoal da igreja e elas me disseram que existe uma coisa e outra né... o mal e o bem e eu não tenho muito o que dizer desses vizinhos não, mas eles tem muito o que me dizer que eles fazem coisas assim. De uma hora para outra eu caí doente com umas palavras malditas de uma pessoa lá.

O mal não está nele, é através de acontecimentos exteriores que a doença se instala. Sua experiência de ser acometido com a DRC agora é encarada como destino, algo que ele deve aceitar e se isenta da responsabilidade. Ele não se culpa por ter desenvolvido a DRC, cuidava de sua saúde e não cometia exageros em relação à dieta, desta 
forma ele não foi o responsável por a doença. As forças externas que influíram para que ele viesse a desenvolver apesar dos cuidados que tinha.

\section{Destino como aceitação de sua condição}

Não compete ao paciente, compete ao profissional ver à necessidade. Mas a gente deixa se quiser. Ser avaliado melhor, porque laboratório pode errar, eles podem errar, pode não fazer direito o exame e a pessoa ser penalizada. Porque uma coisa é você tá sentindo muitos sintomas que a levam a aquilo, né? Outra coisa é você não estar sentindo essas coisas. Porque tudo foi precipitado, mas eu não sei se tinha essa necessidade toda, tamanha, eu não tive escolha não... Agora o profissional é quem sabe, né? Eu conheço gente que tá na pista a mais tempo do que eu e não fez não (hemodiálise), tem tratamento mas não fez, tá entendendo? Mas é assim que tem que ser...

O participante recupera a capacidade crítica, de autonomia, de escolha. Este se sente atingido pelo mal na forma de sua doença. Como acreditava que estava a serviço do bem na luta contra o mal, encontrou a resposta para suas dúvidas e assim o tratamento médico passou a fazer sentido. Portanto, o participante segue as ordens médicas como estratégia de sobrevivência para continuar lutando.

\section{Considerações finais}

Percebe-se o impacto emocional na forma de compreender a doença experimentada pelo participante do estudo. Mesmo o diagnóstico da DRC como de outras morbidades estarem embasados em um racionalismo técnico - cientifico, os afetos vividos com o impacto do diagnóstico estão presentes. A forma como o paciente enxerga a doença e seu ingresso na hemodiálise é sentido de forma pessoal e singular. Sua experiência apresentou alguns momentos caóticos e de descrença de que a hemodiálise seria realmente a terapêutica correta a ser adotada em seu caso. A experiência e o significado dado a este momento veio à frente de todos os sintomas físicos experimentados, apesar de ter uma boa leitura dos sintomas apresentados não significa que este seja portador da DRC.

Sentir-se doente é diferente de estar doente. Apesar de a DRC manifestar-se em seu organismo, o participante não se considerava doente. $\mathrm{O}$ diagnóstico veio acompanhado de uma experiência caótica, pois, apesar de portar uma doença crônica, constatada após a consulta médica, a decisão de aceitar a condição de adoecimento deveria vir acompanhada do sentir-se doente, afetado pelos sintomas da doença.

Desta forma é imprescindível que desde o momento do diagnóstico o profissional médico saiba perceber a forma na qual o paciente compreenda a DRC, visto que os sintomas corporais, laboratoriais e físicos possam não representar a real condição total de estar doente. A linguagem corporal segue linhas diferentes da linguagem emocional. Sabendo compreender como o paciente enxerga o adoecimento a partir do diagnóstico, como este lê os sintomas em seu corpo, a atuação profissional no sentido de favorecer um ambiente no qual este possa discutir acerca da sua condição de saúde poderá implicar em um melhor enfrentamento de tal processo.

A atuação do psicólogo é de suma importância neste ambiente. Como a hemodiálise consiste em uma terapêutica de alto risco e com um elevado potencial de intercorrências que podem influir na adesão do paciente no tratamento. $\mathrm{O}$ suporte psicológico desde o momento do diagnóstico da DRC, início do suporte hemodiálitico e a manutenção de tal suporte durante as sessões de hemodiálise podem ajudar a melhorar a adesão do tratamento e fortalecer o enfrentamento da terapia de substituição renal. Então, desde um acompanhamento anterior a hemodiálise este paciente pode entrar mais fortalecido no tratamento e compreendendo como o adoecimento pode manifestar-se.

\section{Referências}

Barreto, F. C. et al. (2014). Em busca de uma melhor compreensão da doença renal crônica: uma atualização em toxinas urêmicas. Jornal Brasileiro de Nefrologia, 36(2), 221-235.

Barros, E. (2003). Nefrologia: rotinas, diagnóstico e tratamento. (3. ed). Porto Alegre: Artmed.

Bastos, M. G., Bregman, R., \& Kirsztajn, G. M. (2010). Doença renal crônica: frequente e grave, mas também prevenível e tratável. Revista da Associação Médica Brasileira, São Paulo, $56(2)$.

Canguilhem, G. (2000). O normal e o Patológico. Rio de Janeiro: Forense-Universitária.

Chan, R, Brooks, R, Erlich, J, \& Suranyi, M. (2009). The effects of kidney-disease-related loss on long-term dialysis patients' depression and quality of life: positive affect as a mediator. Journal American Society Nephrology (Washington), 4(1), 160-167.

Correa, A. K. (1997). Fenomenologia: uma alternativa para pesquisa em enfermagem. Revista Latino Americana de Enfermagem (Ribeirão Preto), 5(1), 83-88.

Diretrizes Brasileiras de Doença Renal Crônica. (2004). Jornal Brasileiro de Nefrologia, 26, p. 49.

Fernandes, M. A. (2011). Do cuidado da fenomenologia à fenomenologia do cuidado. Em Adão José Peixoto \& Adriano Furtado Holanda (Orgs). Fenomenologia do cuidado e do cuidar: perspectivas multidisciplinares (p. 17-27). Curitiba: Juruá.

Ferreira, R. C., \& Filho, C. R. S. (2011). A qualidade de vida dos pacientes renais crônicos em hemodiálise na região de Marília, São Paulo. Jornal Brasileiro de Nefrologia (São Paulo), 33(2), 129-135. 
Gadamer, H. G. (2006). O caráter oculto da saúde. Rio de Janeiro: Vozes.

Gil, A.C. (2009). Estudo de caso: Fundamentação científica, subsídios para coleta e análise dos dados, como redigir o relatório. São Paulo: Atlas.

Giorgi, A. \& Souza, D. (2010). Método Fenomenológico de Investigação em Psicologia. Portugal: Lisboa.

Husserl, E. (2006). Idéias para uma fenomenologia pura e para uma filosofia fenomenológica: introdução geral á fenomenologia pura. São Paulo: Idéias \& Letras.

Jones, C., Rolderick, P., Harris, S. \& Rogerson, M. (2006). Decline in kidney function before and after nephrology referral and the effect on suvirval in moderate advanced chronic kidney disease. Nephrology Dialisis Transplant, 21, 2133-2143.

Machado, L. R. C. \& Car, M. R. (2003). A dialética da vida cotidiana de doentes com insuficiência renal crônica: entre o inevitável e o casual. Revista da Escola de Enfermagem da USP (São Paulo), 37(3), 27-35.

Marques, A., Pereira, D. C. \&Ribeiro, R. C. H. M. (2005). Motivos e freqüência de internação dos pacientes com IRC em tratamento hemodialítico. Arq. Ciênc. Saúde (Brasília), 12(2), 67-72.

Martins, M. R. I. \& Cesarino, C. B. (2005). Qualidade de vida de pessoas com doença renal crônica em tratamento hemodialítico. Revista Latino-americana de Enfermagem (Ribeirão Preto), 13(5), 670-676.

Olivieri, D. (1985). O "ser doente": Dimensão humana na formação do profissional de saúde. São Paulo: Moraes.

Padovani, C. S. S., Schor, N. \& Laranja, S. M. R. (2012). Avaliação do perfil epidemiológico e das dificuldades encontradas pelos pacientes para o atendimento de primeira consulta no ambulatório de triagem da nefrologia da UNIFESP. Jornal Brasileiro de Nefrologia (São Paulo), 34(4), 317-322.

Rolland, J. S. (1998). Ajudando Famílias com perdas antecipadas. In F.Walsh \& M. Mcgoldrick. Morte na família: sobrevivendo às perdas. Porto Alegre: Artes Médicas.

Silva-Junior, J. B. (2009). As doenças transmissíveis no Brasil: tendências e novos desafios para o Sistema Único de Saúde. Ministério da Saúde, ed. Saúde Brasil 2008: 20 anos de Sistema Único de Saúde (SUS) no Brasil. Brasília: Ministério da Saúde.

Valle L. S., Souza V. F.; Ribeiro A. M. (2013). Estresse e ansiedade em pacientes renais crônicos submetidos à hemodiálise. Estudos de Psicologia (Campinas), 30(1), 131-38.

WHO-World Health Organization. (2014). Global burden of disease study. Disponível em: <http://www3.who.int/whosis/ menu.cfm?path $=$ evidence, burden\&language $=$ english $>$. Acesso em: 16 de nov de 2014.
Rhayssa Ferreira Brito - Graduada em Psicologia pela Universidade Católica de Pernambuco (UNICAP) e Mestranda no Programa de Pós Graduação em Saúde da Criança e do Adolescente da Universidade Federal de Pernambuco (UFPE). Endereço: Rua Frei Jaboatão, 280, Bloco F Apt 603. Torre, Recife-PE. Cep: 50710-030. E-mail: rhayssabrito@hotmail.com Telma Costa de Avelar - Graduada em Psicologia pela Universidade Federal de Pernambuco, com Mestrado em Psicologia Cognitiva pela Universidade Federal de Pernambuco. Atualmente é Professora Assistente da Universidade Federal de Pernambuco.

Marcus Tulio Caldas - Doutor em Psicologia pela Universidade de Deusto. Atualmente é médico psiquiatra do Governo do Estado de Pernambuco e Professor Adjunto da Universidade Católica de Pernambuco.

Luciana Fernandes Santos - Graduada em Psicologia pela Universidade Federal da Paraíba e Mestranda no Programa de Pós Graduação em Saúde da Criança e do Adolescente, na Universidade Federal de Pernambuco.

Fernanda Paula dos Santos Castro - Graduada em Psicologia pela Universidade Federal de Pernambuco, com Especialização em andamento em Residência multiprofissional integrada em saúde, na Universidade Federal de Pernambuco.

Brena da Cruz Prado - Graduada em Psicologia pela Faculdade dos Guararapes, com Especialização em andamento em Residência Multiprofissional Integrada em Saúde, na Universidade Federal de Pernambuco.

Recebido em 01.06.2016 Primeira Decisão Editorial em 30.09.2016 Aceito em 20.10.2016 